\title{
Disruption of rimP-SC, encoding a ribosome assembly cofactor, markedly enhances the production of several antibiotics in Streptomyces coelicolor
}

\author{
Yuanyuan Pan ${ }^{\dagger}$, Cheng Lư ${ }^{\dagger}$, Hailing Dong, Lingjun Yu, Gang Liu* and Huarong Tan*
}

\begin{abstract}
Background: Ribosome assembly cofactor RimP is one of the auxiliary proteins required for maturation of the $30 \mathrm{~S}$ subunit in Escherichia coli. Although RimP in protein synthesis is important, its role in secondary metabolites biosynthesis has not been reported so far. Considering the close relationship between protein synthesis and the production of secondary metabolites, the function of ribosome assembly cofactor RimP on antibiotics production was studied in Streptomyces coelicolor and Streptomyces venezuelae.
\end{abstract}

Results: In this study, the rimP homologue rimP-SC was identified and cloned from Streptomyces coelicolor. Disruption of rimP-SC led to enhanced production of actinorhodin and calcium-dependent antibiotics by promoting the transcription of actll-ORF4 and cdaR. Further experiments demonstrated that MetK was one of the reasons for the increment of antibiotics production. In addition, rimP-SC disruption mutant could be used as a host to produce more peptidyl nucleoside antibiotics (polyoxin or nikkomycin) than the wild-type strain. Likewise, disruption of rimP-SV of Streptomyces venezuelae also significantly stimulated jadomycin production, suggesting that enhanced antibiotics production might be widespread in many other Streptomyces species.

Conclusion: These results established an important relationship between ribosome assembly cofactor and secondary metabolites biosynthesis and provided an approach for yield improvement of secondary metabolites in Streptomyces.

Keywords: rimP-SC, Streptomyces coelicolor, Actinorhodin, Calcium-dependent antibiotics

\section{Introduction}

In bacteria, more than $90 \%$ of energy is used in protein synthesis [1]. A large amount of them is used in ribosome assembly and protein translation. In vitro experiments have revealed that $50 \mathrm{~S}$ and $30 \mathrm{~S}$ ribosomal subunits could be reconstituted into active ribosomes from isolated components through heat-activation steps under different magnesium concentrations. However, these steps are not required and auxiliary proteins are needed in vivo [2]. An increasing number of ribosome assembly factors have

\footnotetext{
*Correspondence: liug@ im.ac.cn; tanhr@ im.ac.cn

${ }^{\dagger}$ Equal contributors

Institute of Microbiology, Chinese Academy of Sciences, Beijing 100101, China
}

been identified for $30 \mathrm{~S}$ subunit reconstitution, such as RimP, RimM and RbfA in Escherichia coli [2].

RimP, formerly known as YhbC or P15a, is encoded by $\operatorname{rim} P$ in the $r b f A$ operon and required for the maturation of $30 \mathrm{~S}$ subunit. RimP is associated with $30 \mathrm{~S}$ subunit but not $50 \mathrm{~S}$ subunit or $70 \mathrm{~S}$ ribosome. In the $\operatorname{rim} P$ deletion mutant, immature 16S rRNA is accumulated and the ribosomal profile shows fewer polysomes and the accumulation of unassociated $30 \mathrm{~S}$ and $50 \mathrm{~S}$ subunits. The difference becomes more obvious with the increasing temperature. The slow growth of $\operatorname{rim} P$ deletion mutant could not be suppressed by the increased expression of other known $30 \mathrm{~S}$ maturation factors [2]. In vitro assembly studies showed that the preincubation of RimP with $16 \mathrm{~S}$ rRNA could accelerate the binding rates of the $5^{\prime}$ 
domain ribosomal proteins $\mathrm{S} 5$ and $\mathrm{S} 12$ to almost all of the 3' domain proteins (S3, S7, S9, S10, S13, and S14) $[3,4]$.

Streptomyces coelicolor is the genetically most studied streptomycete and used as a model strain for studying the biology of actinomycetes [5,6]. It produces at least four distinct classes of antibiotics [6], including the wellknown blue-pigmented aromatic polyketide antibiotic actinorhodin (ACT) which provides an easily tractable system for the methodological study of strain improvement [7], the red oligopyrrole prodiginine antibiotics (RED) [8], the acidic lipopeptide calcium-dependent antibiotics (CDA) [9] and methylenomycin [10]. The complete sequence and annotation of the S. coelicolor genome provide a way for its rational manipulation to identify potentially novel pathway products, and 29 predicted secondary metabolic gene clusters have been identified so far $[11,12]$. Besides screening new compounds, improving the production of existing compounds is still an important object, especially for the clinically and agriculturally applied antibiotics. Current main methods of improving antibiotics production include classical random mutation and ribosome engineering by the introduction of ribosomal protein mutations conferring drug resistance [13,14]. Although random mutation has played an important role in industry, its random nature is main drawback. In contrast, ribosome engineering approach allows for more rational manipulation.

In this paper, we cloned a $\operatorname{rim} P$ homologous gene rimP-SC from $S$. coelicolor and disruption of rimP-SC significantly increased the production of ACT and CDA. Meanwhile, the rimP-SC disruption mutant used as a heterologous expression host could produce more polyoxin or nikkomycin than the wild-type strain. In addition, disruption of rimP-SV also markedly improved jadomycin production in Streptomyces venezuelae, indicating that disruption of rimP homologues might be a widespread method for improving antibiotics production in Streptomyces.

\section{Results}

\section{Identification of rimP homologue in S. coelicolor}

SCO5703 encodes a hypothetical protein consisting of 177 amino acids with a predicted molecular mass of $19.6 \mathrm{kDa}$. Comparative analysis demonstrated that its amino acid sequence was relatively conserved in actinomycetes (Figure 1A). However, its functional analysis has not been reported so far. Sequence alignment showed that it has $27 \%$ identity ( $41 \%$ similarity) with the RimP from E. coli (Figure 1B). Gene organization demonstrates that SCO5703 is flanked by genes similar to those found in $E$. coli, including the transcription elongation factor gene $n u s A$, the translation initiation factor gene $i n f B$, the ribosome binding factor gene $r b f A$ and the tRNA pseudouridine synthase gene truB (Figure 1C). The deduced product of SCO5703 contains the eukaryotic Sm or Sm-like (LSm) domain which associates with RNA to form the core domain of the ribonucleoprotein particle involved in a variety of RNA processing events including pre-mRNA splicing, telomere replication and mRNA degradation, making it a likely target for binding with the $30 \mathrm{~S}$ ribosomal subunit in $S$. coelicolor.

To study the function of SCO5703, E. coli rimP disruption mutant (rimPDM) was constructed by PCR-targeting strategy. Then, the heterologous complemented strain of rimPDM (rimPDMC) was also constructed. Finally, the growth rates of $E$. coli wild-type strain BW25113, rimPDM and rimPDMC were detected at $28^{\circ} \mathrm{C}, 37^{\circ} \mathrm{C}$ or $42^{\circ} \mathrm{C}$. As reported previously [2], rimPDM showed a reduced growth rate, especially at higher temperature. Introduction of the intact SCO5703 into the rimPDM restored the slow-growth phenotype almost to the wild-type level, indicating that SCO5703 is a functional homolog of E. coli $\operatorname{rim} P$ and thus is designated as rimP-SC (data not shown).

\section{Disruption of rimP-SC enhances antibiotics production in Streptomyces}

In order to clarify the function of rimP-SC in vivo, its disruption mutant (rimP-SCDM) was constructed via homologous recombination in S. coelicolor M145. Disruption of rimP-SC reduced the growth rate of $S$. coelicolor at initial period of rapid growth in GYM medium (Figure 2A). Interestingly, the ACT production of rimP-SCDM was remarkably increased 3-fold compared with the wild-type strain (Figure 2B). The growth rate and ACT production of the rimP-SC complemented strain (rimP-SCDMC) lay between the wild-type strain and rimP-SCDM (Figure 2A and $\mathrm{B}$ ), suggesting that disruption of $\operatorname{rimP}-S C$ is the key reason for the enhancement of ACT production. Unlike ACT production, RED production of rimP-SCDM was similar to that of M145 in GYM medium (data not shown). Disruption of rimP-SC also enhanced CDA production in DNA medium (Figure $2 \mathrm{C}$ ).

To examine the function of $\operatorname{rim} P$ homologues in other streptomycetes, the $\operatorname{rim} P$ homologous gene $\operatorname{rim} P-S V$ was disrupted in S. venezuelae. As in S. coelicolor, disruption of rimP-SV remarkably reduced the growth rate of $S$. venezuelae in liquid MYM medium. And the growth rate of complemented strain (rimP-SVDMC) was almost restored to the level of the wild-type strain (Figure 3A). HPLC analysis showed that the production of jadomycin $\mathrm{B}$ had 2-3 folds increase in the rimP-SV disruption mutant (rimP-SVDM) (Figure $3 \mathrm{~B}$ and $\mathrm{C}$ ). Meanwhile, the jadomycin $\mathrm{B}$ production in the complemented strain was almost restored to the wild-type level, albeit slightly higher than the wild-type strain (Figure $3 \mathrm{~B}$ and $\mathrm{C}$ ). The disruption and complementation experiments suggested that $\operatorname{rimP}-S V$ was a key determinant in jadomycin $\mathrm{B}$ 


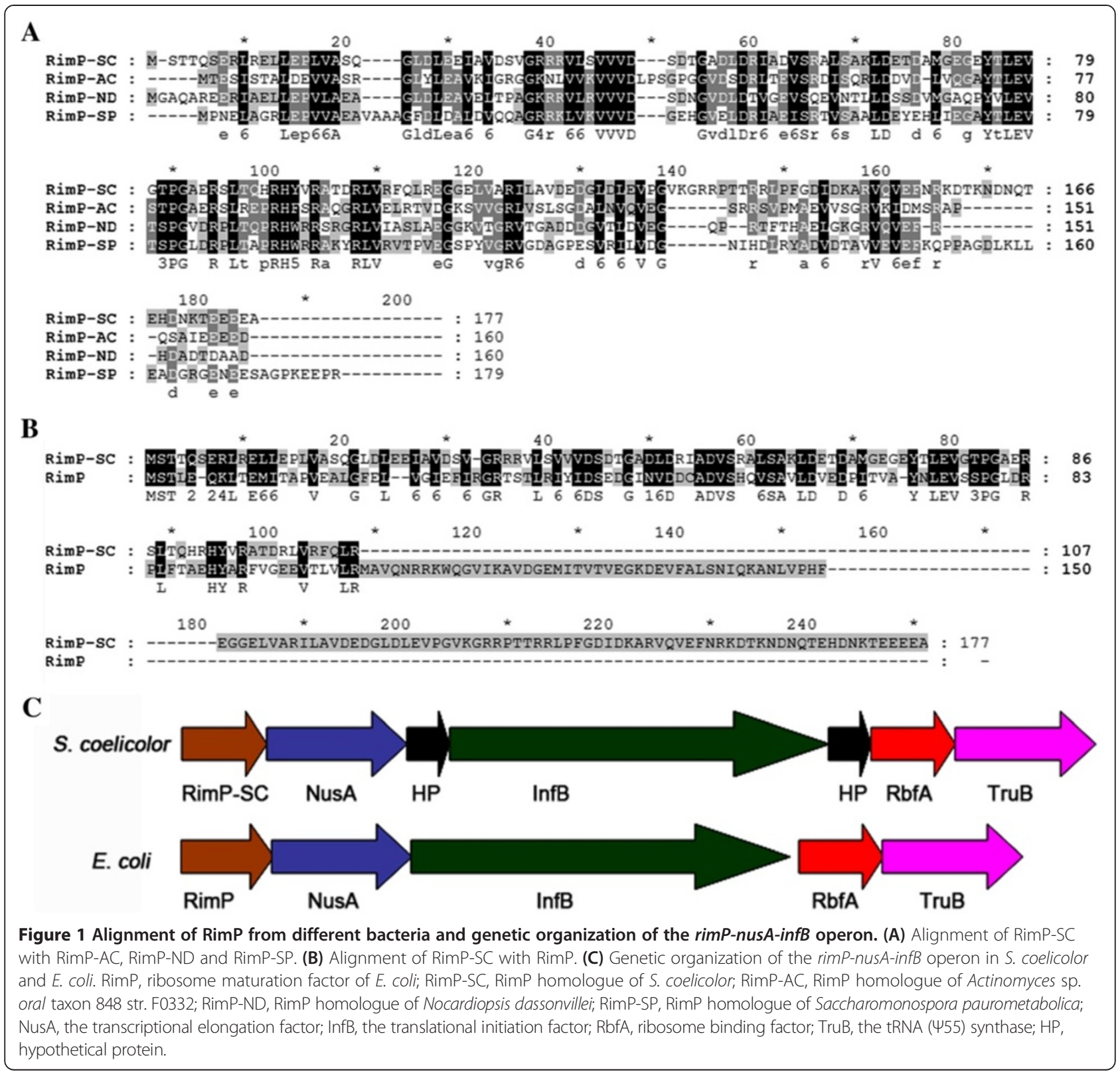

biosynthesis. Transcriptional analysis further confirmed that the increment of jadomycin production was due to the increased transcription of jadomycin biosynthetic genes (Figure 3D). Thus, the stimulatory effect on antibiotics production owing to the disruption of $\operatorname{rim} P$ homologues is not confined to one Streptomyces species.

\section{Transcriptional analysis of actll-ORF4, redD and cdaR}

To explain the reasons for the enhanced production of several distinct antibiotics in rimP-SCDM, the transcription of corresponding biosynthetic genes were measured by real-time RT-PCR. The transcriptional levels of their pathway specific regulatory genes (actII-ORF4, redD, $c d a R$ ) involved in the biosynthesis of three well-known antibiotics (ACT, RED and CDA) were determined in M145 and rimP-SCDM. The transcription of actII-ORF4 reached the highest level in rimP-SCDM at $120 \mathrm{~h}$ and was 3-fold higher than that in M145 (Figure 2D). Consistent with ACT production and transcription of actIIORF4, the transcriptional levels of SCO5072, SCO5082, SCO5086 and SCO5087 involved in ACT biosynthesis were also increased in rimP-SCDM (data not shown). Consistent with RED production, the transcriptional level of redD had no significant difference between rimP-SCDM and M145 (data not shown). The transcriptional level of $c d a R$ in rimP-SCDM exceeded 6-fold more than that in M145 at $24 \mathrm{~h}$, and the difference was narrowed from $72 \mathrm{~h}$ to $120 \mathrm{~h}$ (Figure 2E). Through the 








D

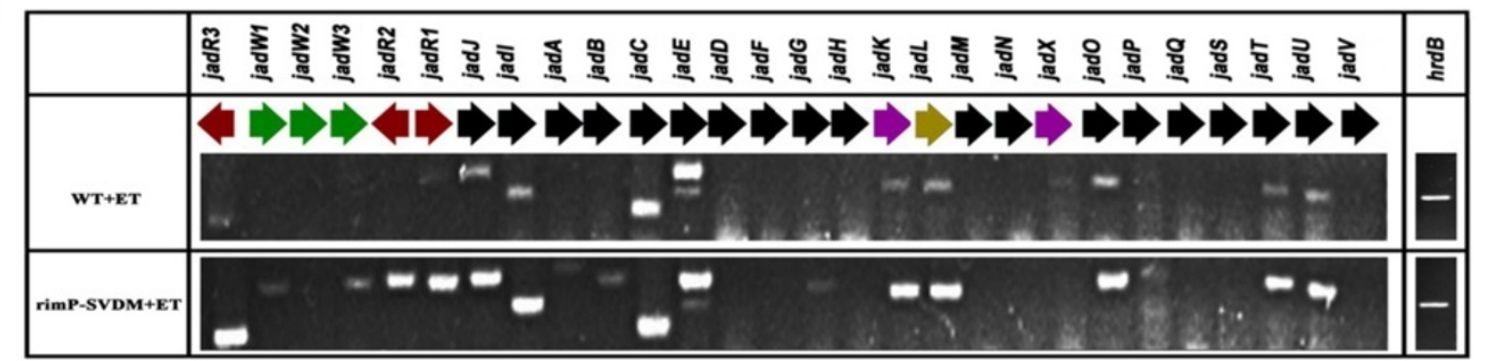

Figure 3 Effects of rimP-SV disruption on biomass and jadomycin B production. (A) Growth curve of the S. venezuelae wild-type strain (WT), rimP-SVDM and rimP-SVDMC with ethanol (ET) induction. Biomass was calculated by mycelium dry weight. (B) The yield of jadomycin B (JdB) in WT, rimP-SVDM and rimP-SVDMC. (C) HPLC analyses of fermentation filtrates from WT, rimP-SVDM and rimP-SVDMC grown for $48 \mathrm{~h}$. mAU, milli absorbance units. (D) Transcriptional analysis of jadomycin B biosynthetic gene cluster by RT-PCR. Total mycelial RNA extracted after $24 \mathrm{~h}$ fermentation was used as template.

transcriptional analysis of the pathway-specific regulatory genes actII-ORF4/cdaR and biosynthetic genes involved in the ACT/CDA production, we might conclude that rimP$S C$ affects the ACT/CDA biosynthesis by controlling the transcription of pathway-specific regulatory gene actIIORF4/cdaR and ACT/CDA biosynthetic genes.

RimP affects the translational efficiency and fidelity in $E$. coli As a ribosome assembly cofactor, RimP may affect translational efficiency. Thus, the translational accuracy was measured using the mutated $x y l E$ as a reporter which contains a UGA stop codon instead of a UGG tryptophan codon at 47 position. When the stop codon was decoded by a near-cognate tRNA, the full length catechol dioxygenase was expressed and showed enzyme activity. To check the expression of catechol dioxygenase, all recombinant strains (BW25113/pSET152::rrnFp::xylE, rimPDM/pSET152::rrnFp::xylE, BW25113/pSET152::rrnFp:: xylE" and rimPDM/pSET152::rrnFp::xylE") were cultured in $\mathrm{LB}$ medium at $37^{\circ} \mathrm{C}$. Under this condition, the growth rate of BW25113 was a little faster than rimPDM (Figure 4A). Meanwhile, the expression level of wild-type catechol dioxygenase in BW25113 was almost the same as rimPDM (Figure 4B). When introducing a UGA stop codon into the wild-type $x y l E$ (named as $x y l E^{*}$ ), the catechol dioxygenase activity decreased 3 orders of magnitude. Meanwhile, the activity of XylE" decreased almost 2-4 folds in rimPDM compared with BW25113 (Figure 4B). As shown in Figure $4 \mathrm{~B}$, the translational error rate of mutated catechol dioxygenase was about $5 \times 10^{-4}$ in BW25113 and $1-2 \times 10^{-4}$ in rimPDM. Therefore, the presence of RimP remarkably increased misreading of the UGA stop codon probably by decoding the near-cognate tRNA. These results implied that the presence of RimP might facilitate misreading of codons to result in the fast growth during exponential phase, but decrease the translational accuracy.

\section{Disruption of rimP-SC significantly enhanced the expression of MetK}

To study how disruption of rimP-SC enhance ACT/ CDA production in $S$. coelicolor, transcriptions of six global activator genes (absR1, adpA, afsR, atrA, metK and $r n c$ ) and three global repressor genes (phoP, ndgR and $s s g A$ ) as well as five sigma factor genes (bldN, sigE, sigH, sigR and $\operatorname{sig} T$ ) were analyzed by real-time RT-PCR. The results indicated that the transcriptions of five activator genes $(a b s R 1, a d p A, a f s R$, atrA and $r n c)$ were increased and the transcriptions of three repressor genes (phoP, $n d g R$ and $s s g A$ ) were decreased in rimP-SCDM (Figure 5). Although the transcriptional changes of these genes could explain the increase of ACT production, it was unclear whether rimP-SC affected antibiotics biosynthesis at the translational level. Therefore, met $K$ and $\operatorname{sig} R$, whose transcription was not changed significantly 

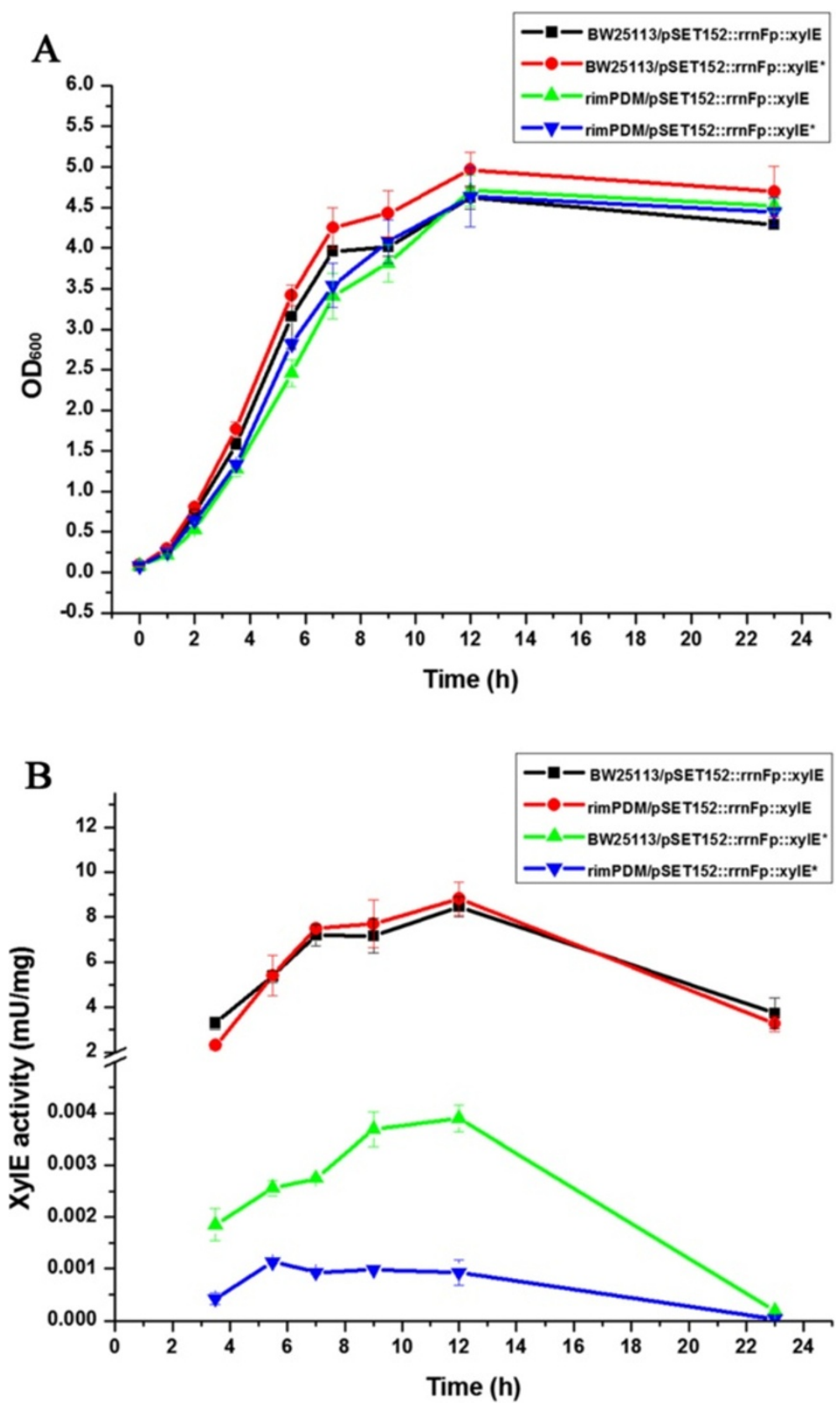

Figure 4 Activity analysis of catechol dioxygenase in E. coli. (A) Growth curve of four different E. coli strains. (B) Activity analysis of the wildtype or mutated catechol dioxygenase. Data were presented as the averages of the results of three independent experiments in triplicate. Error bars showed standard deviations. The asterisk $\left(^{*}\right)$ indicates mutated catechol dioxygenase (UGG codon as tryptophan at 47 position was replaced by UGA as stop codon).

in comparison with the wild-type strain, were selected for further studying their translations. To check the syntheses of MetK and SigR, the flag-tagged system was used. The result of western blotting showed that the expression of MetK was much stronger in rimP-SCDM than M145 from $24 \mathrm{~h}$ to $72 \mathrm{~h}$ (Figure 6A). However, the transcription of met $K$ in rimP-SCDM did not exceed M145 (Figure 6B). In addition, the expression of SigR did not show significant difference between the wildtype strain and rimP-SCDM (data not show). In agreement with previous report [15], our results also showed that over-expression of MetK obviously stimulated ACT production in advance and led to an increase of ACT production up to $140 \%$ compared with the control strain M145/pIJ10500 (Figure 6C). Therefore, disruption of rimP-SC increased translational level of proteins related 


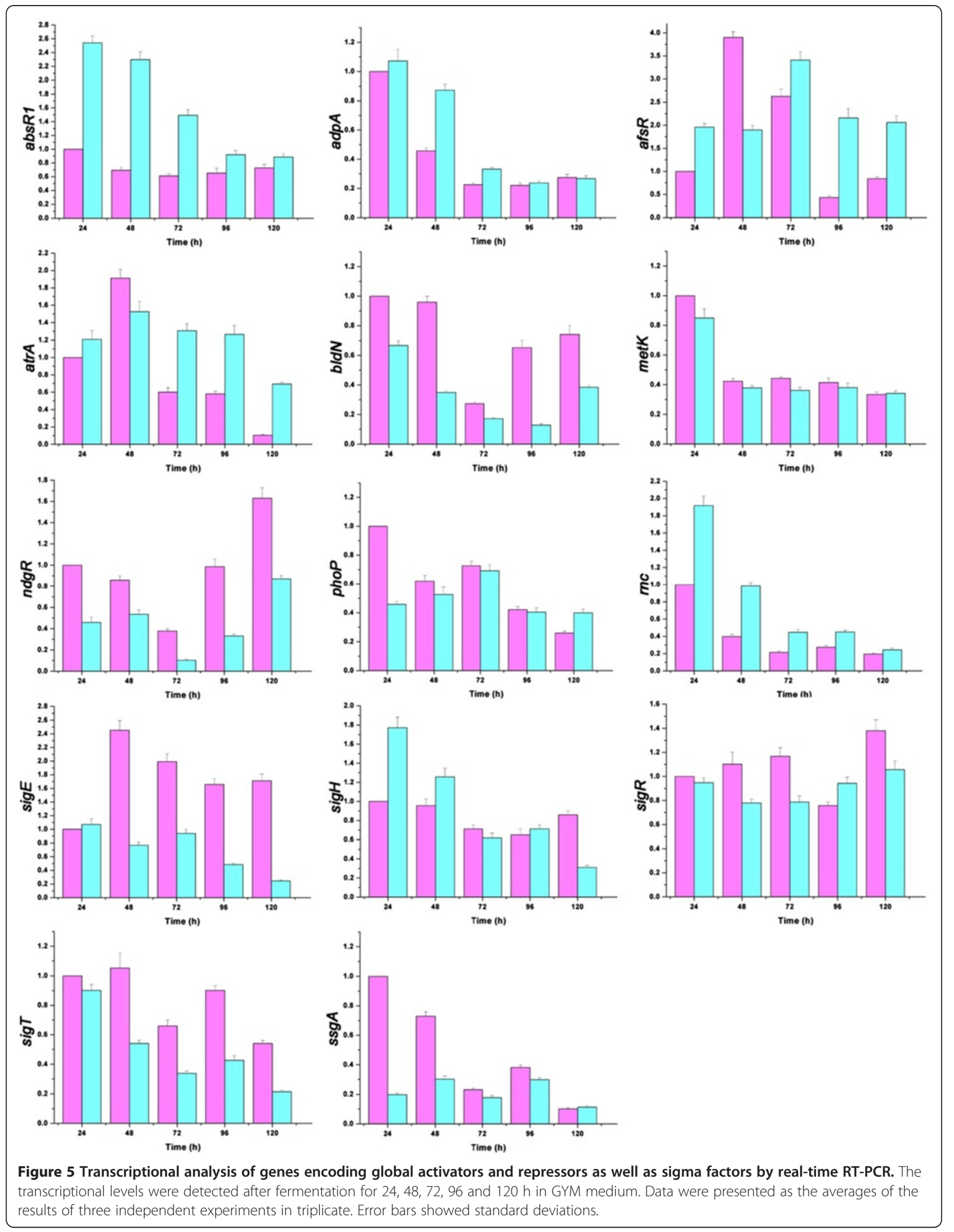




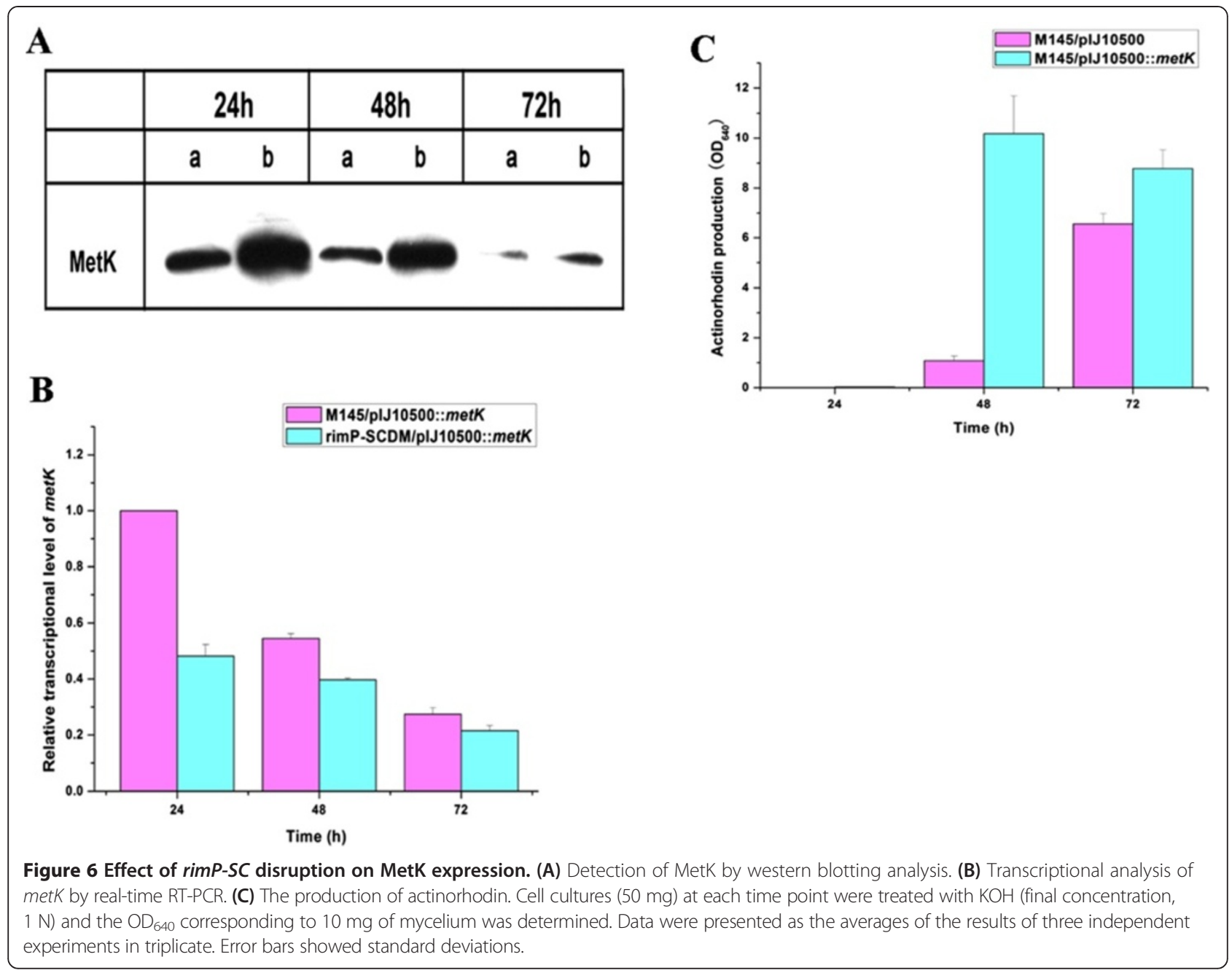

to secondary metabolites, such as MetK which may be one example of many proteins. The complicated mechanism that disruption of $\operatorname{rim} P$ homologues led to enhanced production of antibiotics is intriguing, but remains unclear, so it is worthy of studying and is being explored deeply in our lab at present.

\section{RimP-SCDM improved the production of polyoxin and nikkomycin}

Recombinant strains containing the entire polyoxin or nikkomycin biosynthetic gene cluster were cultured for 5 days and their fermentation broths were measured by bioassay. The results showed that the fermentation broth of rimP-SCDM/pPOL had obvious stronger bioactivity than that of $\mathrm{M} 145 / \mathrm{pPOL}$ against the indicator strain A. longipes (Figure 7A). Meanwhile, the rimP-SCDM /pPOL and M145/pPOL had comparable growth rates and final biomass (data not shown). Subsequently, we checked the transcription of polR involved in the biosynthesis of polyoxin. The results showed that the transcription of polR in rimP-SCDM/pPOL was 8-fold higher than that in M145/pPOL at $24 \mathrm{~h}$ (Figure 7B), which were consistent with the results of bioassay. Meanwhile, the fermentation broth of rimP-SCDM/pNIK had obvious stronger bioactivity than that of $\mathrm{M} 145 / \mathrm{pNIK}$ against the indicator strain $A$. longipes (Figure $7 \mathrm{C}$ ). The transcription of san $G$ encoding a positive regulator for nikkomycin biosynthesis was measured. As expected, the transcription of sanG in the rimP-SCDM/pNIK was increased 2.5-fold compared with M145/pNIK at 24 h (Figure 7D). Above results showed that rimP-SCDM could significantly improve the yield of polyoxin and nikkomycin. Therefore, it is possible that rimP-SCDM can be used as the promising heterologous expression host.

\section{Discussion}

SCO5703 is the homologue of RimP which facilitates the maturation of the $30 S$ subunit in E. coli. Since RimP affects the formation of polysomes in E. coli [2], it is possible that disruption of rimP-SC also reduces the formation of polysomes and leads to the production of $30 \mathrm{~S}$ subunit containing immature $16 \mathrm{~S}$ rRNA in 


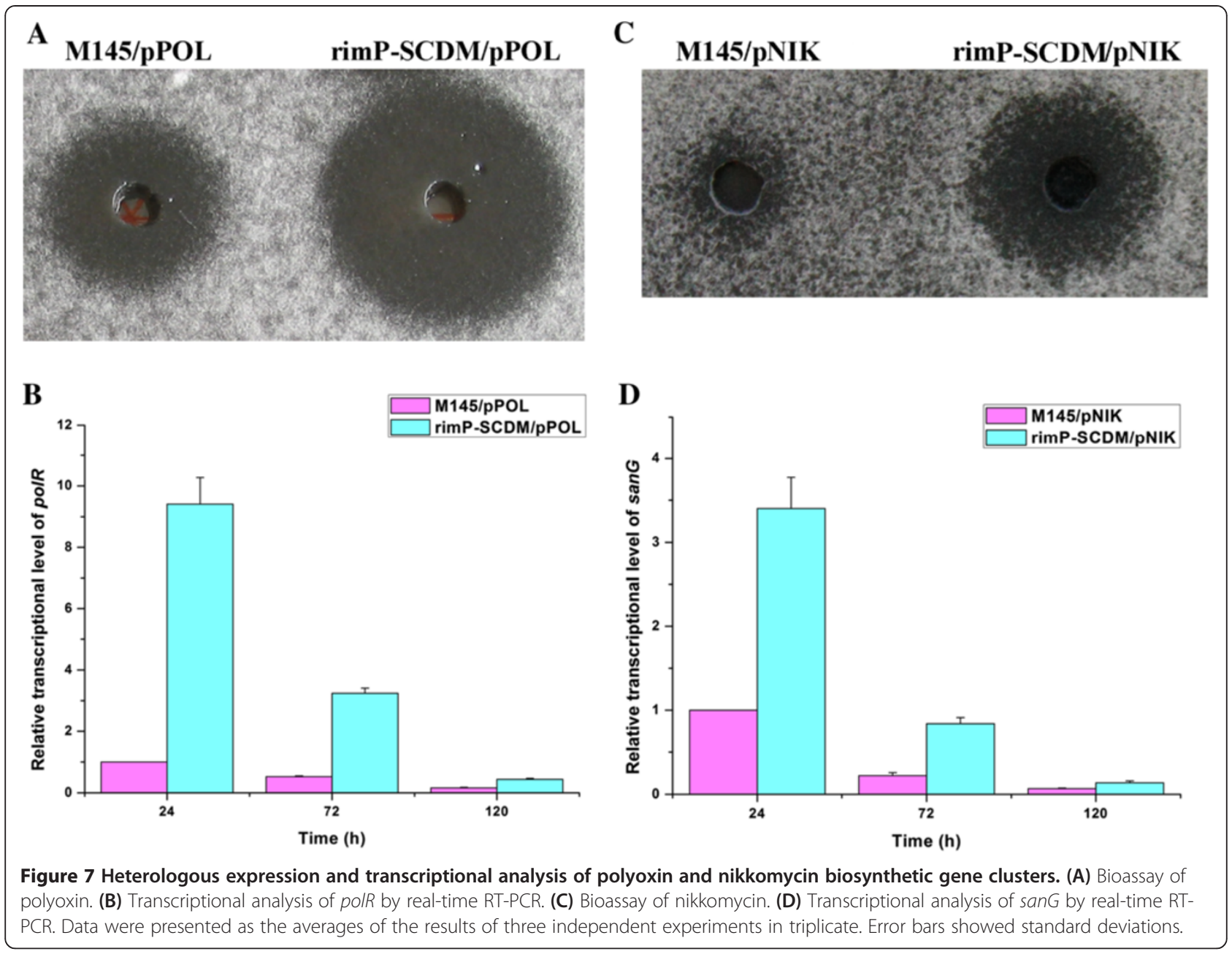

S. coelicolor. In addition, RimP-SC was involved in the antibiotics production in $S$. coelicolor. We postulate that the difference in the growth rate and antibiotics production correlate with the amount of polysomes which affects protein translational capacity.

Ribosomal protein S12, which is located at the interface of $30 \mathrm{~S}$ and $50 \mathrm{~S}$ subunits and closes to the decoding center of the ribosome, is important in maintaining translational accuracy. Contact of S12 and 16S rRNA facilitates the formation of closed conformation of $30 \mathrm{~S}$ ribosomal subunit and hampers the entrance of near-cognate tRNA during translation [16]. The closed conformation activates EF-Tu, GTPase and ribosomes to enter the translational process $[17,18]$. Aside from drug resistance, many S12 mutant strains show pleiotropic effects including translational hyper-accuracy, reduced growth and impaired peptide chain elongation [19]. The K88E mutation of the S12 protein causes a high level of resistance of $S$. coelicolor to streptomycin and stimulates the production of ACT [20]. These phenomena might be due to the increased protein synthesis during the late growth phase and the enrichment of ribosome recycling factor RRF [21]. The phenomenon that disruption of rimP-SC increases protein synthesis at the late growth phase is similar to the K88E mutant of S12 protein $[22,23]$. Unlike the K88E mutant, deletion of rimP-SC may not increase the stability of $70 \mathrm{~S}$ ribosome as the rimP mutant only hindered the maturation of $30 \mathrm{~S}$ subunit and did not result in the change of S12 protein in E. coli [2]. In addition, accumulation of ppGpp stimulates antibiotics production in S. coelicolor [24]. The increased production of ACT in S12 mutant results from higher level of ppGpp [25]. However, the amount of ppGpp had no obvious difference between M145 and rimP-SCDM in our study (data not shown), indicating that ppGpp was not the reason for improved production of ACT in RimPSCDM. The similar phenomenon that the hyperaccurate ribosomes exhibited slightly reduced rates of GTP hydrolysis for both cognate and near-cognate ternary complexes has been reported [26]. Therefore, the reasons for stimulating antibiotics production due to rimP-SC disruption are different from the mutation of $\mathrm{S} 12$ protein in S. coelicolor. 
The onset of protein synthesis is determined by tRNA selection. Generally, the tRNA selection is divided into an initial selection and a later proofreading process. During initial selection, cognate aminoacyl-tRNA facilitates the stabilization of a closed $30 \mathrm{~S}$ conformation. However, nearcognate aminoacyl-tRNA, which differs from cognate tRNA by a single, subtle mismatch in codon-anticodon base-pairing and cannot be accurately distinguished on the basis of difference in the free energy of base-pairing alone, is not disadvantage for the stabilization of a closed $30 \mathrm{~S}$ conformation [17]. Stabilization of the closed form of $30 \mathrm{~S}$ ribosomal subunit could reduce the translational fidelity and increase the translational speed. The translational accuracy was measured using $x y l E$ gene as a reporter in $E$. coli wild-type strain and rimPDM. The results showed that RimP might stabilize the closed form and accelerate the reconstitution of $30 \mathrm{~S}$ ribosomal subunit induced by cognate or near-cognate tRNA, thus speeding up the translation. Without RimP, the closed 30 S form might be unstable and unfavorable for selection of near-cognate tRNA, thus leading to higher translation fidelity and lower translation speed.

\section{Conclusions}

As in E. coli, RimP-SC encoded a cofactor involved in ribosome assembly of the $30 \mathrm{~S}$ subunit and its disruption reduced growth rate at initial period of rapid growth in $S$. coelicolor. RimP-SC also played an essential role in actinorhodin and calcium-dependent antibiotics production. Disruption of rimP-SC enhanced expression of MetK and protein translational accuracy, resulting in increased antibiotics production. This is the first study to address the relationship between ribosome assembly cofactor and antibiotics production. Our results provided an approach for yield improvement based on rimP homologues disruption, which was also effective in $S$. venezuelae, implying that the approach might be adopted to increase antibiotics production in other Streptomyces species. Ultimately, more peptidyl nucleoside antibiotics-polyoxin and nikkomycin could be produced in rimP-SC disruption mutant than M145, indicating that rimP-SC disruption mutant could be used as a promising host for heterologous expression.

\section{Materials and methods}

Bacterial strains, plasmids, primers, growth conditions and assay of antibiotics

Bacterial strains and plasmids used in this study were listed in Table 1. The primers used in this study were listed in Table 2. E. coli JM109 was used as a general host for routine cloning experiment. BW25113 was used as an $E$. coli host for the construction of rimP disruption mutant via $\lambda$-Red-mediated recombination technology. E. coli ET12567/pUZ8002 was used as a host for transferring DNA from E. coli to Streptomyces by intergeneric conjugation. S. coelicolor M145 was a derivative of the wild-type strain S. coelicolor A3(2) lacking plasmids SCP1 and SCP2. S. venezuelae ATCC10712 was the wild-type strain of $S$. venezuelae. Alternaria longipes was the indicator strain of polyoxin and nikkomycin. Staphylococcus aureus was the indicator strain of calcium-dependent antibiotics (CDA). Usually, E. coli and its derivatives were grown at $37^{\circ} \mathrm{C}$. Streptomyces and their derivatives were grown at $28^{\circ} \mathrm{C}$. Yeast extract-malt extract liquid medium (YEME), GYM medium, Difco Nutrient Agar (DNA) medium supplemented with $0.5 \% \mathrm{NaCl}(\mathrm{w} / \mathrm{v})$ and agar minimal medium (MM) supplemented with mannitol as sole carbon source were prepared for growth and sporulation of Streptomyces as described previously [6]. SP medium (3\% mannitol, $1 \%$ soluble starch, $0.75 \%$ yeast extract, and $0.5 \%$ soy peptone, $\mathrm{pH}$ 6.0) for polyoxin and nikkomycin production was prepared as described previously [27]. Potato dextrose agar medium (PDA) for the detection of polyoxin and nikkomycin was used. MYM medium for jadomycin production was prepared as described previously [28]. For the production of ACT and RED, fresh spores of $S$. coelicolor were inoculated in GYM medium as described previously [6]. ACT and RED were detected spectrophotometrically [6]. CDA production in DNA medium was assayed as described previously [29]. Jadomycin production was measured as described previously [28,30,31]. For fermentation, spore suspensions of S. venezuelae were inoculated in MYM and grown at $28^{\circ} \mathrm{C}$ on a rotary shaker $(220 \mathrm{rpm})$ for $24 \mathrm{~h}$ as seed cultures. $5 \mathrm{ml}(5 \% \mathrm{v} / \mathrm{v})$ of seed culture was transferred into flasks containing $100 \mathrm{ml}$ of galactose-isoleucine medium with $1.5 \mathrm{ml}$ ethanol, and then cultured at $28^{\circ} \mathrm{C}$ on a rotary shaker $(220 \mathrm{rpm})$ for jadomycin production. Jadomycin B was identified by HPLC analysis (Agilent 1260 HPLC and RPC-18) at $316 \mathrm{~nm}$ absorption wavelengths. Chemical reagent, mobile phase and gradient elution process were performed as described previously [31].

Plasmids pBluescript KS+, pEASY-Blunt and pUC119:: kan were used for routine cloning experiments in E. coli. The Streptomyces-E. coli shuttle plasmid pKC1132 was used to construct gene disruption mutants via homologous recombination. The integrative plasmid pSET152 was used to introduce a single copy of rimp homologue gene into the Streptomyces chromosome. pIJ10500 containing hygromycin B (hyg) resistance gene and $3 \times$ FLAG tag was used in western blotting experiment. The $x y l E$ from pIJ4083 was used for the construction of the reporter system. When necessary, antibiotics were used at the following concentrations: ampicillin $\left(100 \mu \mathrm{g} \cdot \mathrm{ml}^{-1}\right)$, kanamycin $\left(100 \mu \mathrm{g} \cdot \mathrm{ml}^{-1}\right)$, apramycin $\left(100 \mu \mathrm{g} \cdot \mathrm{ml}^{-1}\right)$ or hygromycin B $\left(50 \mu \mathrm{g} \cdot \mathrm{ml}^{-1}\right)$ in LB for E. coli; Nalidixic acid $\left(25 \mu \mathrm{g} \cdot \mathrm{ml}^{-1}\right)$, apramycin $\left(100 \mu \mathrm{g} \cdot \mathrm{ml}^{-1}\right)$ or kanamycin $\left(100 \mu \mathrm{g} \cdot \mathrm{ml}^{-1}\right)$ in MS for Streptomyces [6]. 
Table 1 Bacterial strains and plasmids used in this study

\begin{tabular}{|c|c|c|}
\hline Bacterial strains/plasmids & Relevant characteristics & $\begin{array}{l}\text { Source/ } \\
\text { references }\end{array}$ \\
\hline \multicolumn{3}{|l|}{ Streptomyces } \\
\hline S. coelicolor M145 & A derivative of the wild-type strain S. coelicolor A3(2) lacking plasmids SCP1 and SCP2 & {$[6]$} \\
\hline rimP-SCDM & The rimP-SC disruption mutant of S. coelicolor & This study \\
\hline rimP-SCDMC & The complemented strain of rimP-SCDM & This study \\
\hline M145/pNIK & S. coelicolor M145 containing the entire nikkomycin biosynthetic gene cluster & This study \\
\hline $\mathrm{rimP-SCDM/pNIK}$ & rimP-SCDM containing the entire nikkomycin biosynthetic gene cluster & This study \\
\hline M145/pPOL & S. coelicolor M145 containing the entire polyoxin biosynthetic gene cluster & This study \\
\hline $\operatorname{rimP-SCDM} / \mathrm{pPOL}$ & rimP-SCDM containing the entire polyoxin biosynthetic gene cluster & This study \\
\hline S. venezuelae ATCC10712 & The wild-type strain of S. venezuelae & {$[6]$} \\
\hline rimP-SVDM & The rimP-SV disruption mutant of S. venezuelae & This study \\
\hline rimP-SVDMC & The complemented strain of rimP-SVDM & This study \\
\hline \multicolumn{3}{|l|}{ E. coli } \\
\hline JM109 & recA1, endA1, gyrA96, thi-1, hsdR17, supE44, relA1, $\Delta$ (lac-proAB)/F'ttraD36, proAB+, laclq, lacZ $\Delta M 15]$ & Invitrogen \\
\hline BW25113 & K-12 derivative; $\triangle \mathrm{araBAD} \triangle \mathrm{rhaBAD}$ & {$[32]$} \\
\hline ET12567/pUZ8002 & dam dcm hsdS cat tet/pUZ8002 & [33] \\
\hline rimPDM & The rimP disruption mutant of E. coli BW25113 & This study \\
\hline rimPDMC & The heterologous complemented strain of rimPDM & This study \\
\hline $\begin{array}{l}\text { rimPDM/pSET152::rrnFp:: } \\
\text { SCO5703 }\end{array}$ & rimPDM containing pSET152::rrnFp::SCO5703 for heterologous complementation analysis & This study \\
\hline BW25113/pSET152::rrnFp::xylE & BW25113 containing pSET152::rrnFp:::xylE for catechol dioxygenase assay & This study \\
\hline $\begin{array}{l}\text { BW25113/pSET152::rrnFp:: } \\
\text { xylE* }\end{array}$ & BW25113 containing pSET152::rrnFp::xylE* for catechol dioxygenase assay & This study \\
\hline rimPDM/pSET152::rrnFp::xylE & rimPDM containing pSET152::rrnFp::xylE for catechol dioxygenase assay & This study \\
\hline rimPDM/pSET152::rrnFp::xylE** & rimPDM containing pSET152::rrnFp::xylE* for catechol dioxygenase assay & This study \\
\hline \multicolumn{3}{|l|}{ Plasmids } \\
\hline pRIMPSC3 & Plasmid used for the construction of rimP-SCDM & This study \\
\hline pRIMPSC4 & pSET152 containing the intact rimP-SC with its putative promoter & This study \\
\hline pRIMPSV3 & Plasmid used for the construction of rimP-SVDM & This study \\
\hline pRIMPSV4 & pSET152 containing the intact rimP-SV with its putative promoter & This study \\
\hline pSET152:::rrnFp::xylE & $\begin{array}{l}\text { pSET152 containing the wild-type xylE and the promoter of } r r n F \text { for activity detection of catechol } \\
\text { dioxygenase }\end{array}$ & This study \\
\hline pSET152::rrnFp::xylE* & $\begin{array}{l}\text { pSET152 containing the mutated } x y \mid E \text { and the promoter of } r r n F \text { for activity detection of catechol } \\
\text { dioxygenase }\end{array}$ & This study \\
\hline plJ10500::metK & plJ10500 containing the intact metK with its promoter & This study \\
\hline plJ10500::sigR & plJ10500 containing the intact sigR with its promoter & This study \\
\hline pNIK & pSET152 containing the entire nikkomycin biosynthetic gene cluster & {$[34]$} \\
\hline PPOL & pSET152 containing the entire polyoxin biosynthetic gene cluster & [35] \\
\hline
\end{tabular}

\section{Construction of the recombinant strains}

The rimP disruption mutant (rimPDM) of E. coli BW25113 was constructed by PCR targeting as follows: A $1.2 \mathrm{~kb}$ DNA fragment containing the kanamycin resistance gene (kan) was amplified by PCR using primers ECrimP-F and ECrimP-R. This fragment covered the 38-bp upstream region and the 65-bp downstream region of $\operatorname{rimP}$. Then the fragment was purified and introduced into the BW25113 by electroporation. Finally, the kanamycin resistance gene substituted the most of rimP coding region by homologous recombination. The resulting strain was confirmed by PCR amplification using primers YZECrimP-F and YZECrimP-R. In order to clarify the relationship between rimP of E. coli and SCO5703 of S. coelicolor, the heterologous complemented strain was constructed according to the following steps: Firstly, promoter region of $r r n F$ was 
Table 2 Primers used in this study

\begin{tabular}{|c|c|}
\hline Genes and primers & Sequence $\left(5^{\prime}-3^{\prime}\right)$ \\
\hline \multicolumn{2}{|c|}{$\begin{array}{l}\text { rimP homologues relevant } \\
\text { primers }\end{array}$} \\
\hline Lrimp-SC-F & CCCAAGCTTGGCCAGCCGGTCCTCCAGTT \\
\hline Lrimp-SC-R & GCTCTAGAGGTGGTGCTCATCCGGGTGA \\
\hline Rrimp-SC-F & GGGGTACCAGGCCCACCACCCGCAGACT \\
\hline Rrimp-SC-R & GGAATTCCGGCGTGCGGCTTGGATCTA \\
\hline CrimP-SC-F & CGCGGCCAGTTCCTCACTGT \\
\hline CrimP-SC-R & CAGGGCGCTCATGTCGATGT \\
\hline ECrimP-F & $\begin{array}{l}\text { TTGTCCACATTAGAGCAAAAATTAACAGAGA } \\
\text { TGATTACTGGAATTGTGAGCGGATAAC }\end{array}$ \\
\hline ECrimP-R & $\begin{array}{l}\text { TCTGGATATTACTCAGCGCGAACACTTCATCT } \\
\text { TAACCTAAGGCGATTAAGTGGGTAA }\end{array}$ \\
\hline YZECrimP-F & TTGTCCACATTAGAGCAAA \\
\hline YZECrimP-R & TTAAAAGTGGGGAACCAG \\
\hline PFrimP-F & CGGGATCCGACCCACAACAGCACACG \\
\hline PFrimP-R & GCTCTAGATCTCCTTCTCCCGTACCAA \\
\hline LrimP-SV-F & AAGCTTGCCGAACGGTACAGAAAGGGTA \\
\hline LrimP-SV-R & TCTAGATCGCTCTGGGTGGTGCTCATC \\
\hline RrimP-SV-F & GGATCCGGCGAGTACGTCCTCGAAGT \\
\hline RrimP-SV-R & GATATCACCTTGCTCTCCACACCGAACTCC \\
\hline CrimP-SV-F & CGGCGGTTCGAAACCCATGC \\
\hline CrimP-SV-R & CTACGCCTCCTCTTCCTTCTTGTCCTT \\
\hline YZrimP-SV-F & GTGGTACGTCGTCGAAGATC \\
\hline YZrimP-SV-R & GCAAAGCGTCAGTCAACTTG \\
\hline \multicolumn{2}{|c|}{$\begin{array}{l}\text { Primers for real-time PCR of } \\
\text { genes in S. coelicolor }\end{array}$} \\
\hline RTact-F & GCTCCTCAGGCGGCACGA \\
\hline RTact-R & GCCGGCGGGTGTGGTACA \\
\hline RTred-F & GCCCTGACGCGCTATTGG \\
\hline RTred-R & GGTGGTGGGCGAGACGGA \\
\hline RTcda-F & GGAAAGCGACGCCTACTT \\
\hline RTcda-R & AGGCTCGTCTTTCCGATT \\
\hline RTmetK-F & CGAGCCCGTGGGTCTGTT \\
\hline RTmetK-R & CAGGTCGAGAGCGCGGAT \\
\hline RTsigR-F & CGACCACCTGCCCGACTC \\
\hline RTsigR-R & CCCCATGATGTCCGCGAT \\
\hline RTsigE-F & GGAGGAGGTGCCGACCGA \\
\hline RTsigE-R & TTCCCGCCGACATTCCGA \\
\hline RTsigH-F & GGAGCCGCTGGACGACCT \\
\hline RTsigH-R & CACCGCCCAGCCCTTGTC \\
\hline RTbldN-F & GACAGCGCCCGCATGATG \\
\hline RTbldN-R & GAGCGCCCGCAGAAAGGT \\
\hline RTsigT-F & GCCCTCGTCTCCGCCTAC \\
\hline RTsigT-R & CAGGCGTTCGGTGTCGTC \\
\hline RTabsR1-F & CCCGCAGTCGATCATGGA \\
\hline
\end{tabular}

Table 2 Primers used in this study (Continued)

\begin{tabular}{|c|c|}
\hline$\overline{\mathrm{RTabsR1-R}}$ & GCAGGGCGAACTCCTTGTC \\
\hline RTadpA-F & AGCACCTCCACGAGCAGTTC \\
\hline RTadpA-R & CGTCCACCGAGTAGTCCGA \\
\hline RTafsR-F & GGCGGTGGATCTGCTGTG \\
\hline RTafsR-R & ACATCGCTGAGAACGGTGC \\
\hline RTatrA-F & CCGGCGGTGCGATGAGTA \\
\hline RTatrA-R & ACCCCAGCTCGCCGAACA \\
\hline RTndgR-F & CGACGTGACGGGCGAGAG \\
\hline RTndgR-R & GGAGCCGGCCTTCATGGT \\
\hline RTphoP-F & ACGTTCCCGTGATCATGGTG \\
\hline RTphoP-R & CAGTACGGCTCGGATGCG \\
\hline RTrnc-F & GGTGATCGGCGCGGTCTA \\
\hline RTrnc-R & CCTTCGGTCGCGGTGAGT \\
\hline RTssgA-F & CAGGCGCTGTTCCGTTCC \\
\hline RTssgA-R & GATGCGGTCCAGGGCCTC \\
\hline RT5072-F & GACGACCTGCCGCTCAAG \\
\hline RT5072-R & GAACGATGTGCGGTGGGT \\
\hline RT5082-F & GGAGGCCCTGGAGCAGTC \\
\hline RT5082-R & GCCGGCGATGATGATCTC \\
\hline RT5086-F & ACCTCACCGGCGTGTTCC \\
\hline RT5086-R & CGTGCTTCGAGGCGGAGT \\
\hline RT5087-F & GAACGACCGCCACGAGAC \\
\hline RT5087-R & GATCTCCAGCGAGCCGAT \\
\hline RTsanG-F & GGCCACCCTGCAGACGTAC \\
\hline RTsanG-R & CGGGACAGGTCGAACGTG \\
\hline RTpolR-F & GGTCTCCCGCGGACAACA \\
\hline RTpolR-R & GCGGCTCGTAGGACGTGA \\
\hline RThrdB-SC-F & GATCGCCGAGTCCGTCTC \\
\hline RThrdB-SC-R & CACTGAGTGGCCGGAATC \\
\hline \multicolumn{2}{|c|}{$\begin{array}{l}\text { Primers for real-time PCR of } \\
\text { genes in } S \text {. venezuelae }\end{array}$} \\
\hline RTjadR3-F & CACGTGGACGTGACGGATACGG \\
\hline RTjadR3-R & GGGTGTCGGCGAGGTTTCCTTC \\
\hline RTjadW1-F & TCGTCTGCTCCGACATCACCC \\
\hline RTjadW1-R & GCAGGAAGGAGACGCTCAGGTC \\
\hline RTjadW2-F & ACGTACTGATCCACTGCGCCTCC \\
\hline RTjadW2-R & CGATCAGGGAGTGCAGCGAGG \\
\hline RTjadW3-F & ACTACGGCAGCAACGAGAAGGC \\
\hline RTjadW3-R & AGGGCGAGGGTCATCGTGTC \\
\hline RTjadR2-F & TCGGCGATCAGTTCGGGAGC \\
\hline RTjadR2-R & AGCCATTCGCCGTTGTCCC \\
\hline RTjadR1-F & TGGACGGCTTGGAGGTCTGC \\
\hline RTjadR1-R & GGCTGCTCACATGGGTGTCG \\
\hline RTjadJ-F & CTGTCGGAGGCTCAGAACGC \\
\hline RTjadJ-R & ACGATCACGTTCGCAAGCAG \\
\hline
\end{tabular}


Table 2 Primers used in this study (Continued)

\begin{tabular}{|c|c|}
\hline RTjadl-F & TGCACAGCACTCTGATCGTGG \\
\hline RTjadl-R & GCGTTCGCCTCCCAGTTGTAG \\
\hline RTjadA-F & CCCCAACACCGTGGTCTCC \\
\hline RTjadA-R & GCGGTCGTTCTGCTTGGTG \\
\hline RTjadB-F & GGAGCCAGGGCAGCCAGTAC \\
\hline RTjadB-R & CGAAGGTGGAGCCGTATCCG \\
\hline RTjadC-F & GCAGCAAGACCTTCACCCTCG \\
\hline RTjadC-R & CCGACAGGTGCGCGTTGAC \\
\hline RTjadE-F & GCCGACGAGCTGTGGAACG \\
\hline RTjadE-R & GAGGCCAGGTAGCCGACGAG \\
\hline RTjadD-F & GCCTTGCTGCACGACTACCG \\
\hline RTjadD-R & ACGCCGTCCTCGTTCTCCTC \\
\hline RTjadF-F & ACGCCGCTCTGGGTGAACT \\
\hline RTjadF-R & GATGTCGAGTCCTGAGACCTTGC \\
\hline RTjadG-F & ACCTGACCGTCTTCAACCTCTTCG \\
\hline RTjadG-R & TGCTGCTGGTCCGGCTTCAC \\
\hline RTjadH-F & GACGACGACGCCGTGGAGA \\
\hline RTjadH-R & GATGTCCTCGCCCGTGATGC \\
\hline RTjadK-F & CGGCTGCGGACAGGAGTACG \\
\hline RTjadK-R & GAGGCCCAGGCTGATGTTGTG \\
\hline RTjadL-F & GGAAGGAGGAACGGAAGGACG \\
\hline RTjadL-R & ATCAGGGTGTAGAGGGCGAGG \\
\hline RTjadM-F & CCCGCTACACCGGAGTCCC \\
\hline RTjadM-R & GAGTCCCGTGCCGAGTCCC \\
\hline RTjadN-F & GCAGGGTICGGTCTGGAGG \\
\hline RTjadN-R & CGAGGCCGTTCTGGGTGATC \\
\hline RTjadX-F & CCACCACCGACCTCACCG \\
\hline RTjadX-R & CGAAGTGGGCGGAGGGC \\
\hline RTjadO-F & TTCCACAAGTCCAACCGCAAC \\
\hline RTjadO-R & TTCGATCAGCGGCTGGGTC \\
\hline RTjadP-F & AAGCACGTCCTGGCCGAGAAG \\
\hline RTjadP-R & GGTCCATGCCGAAGGCGATGT \\
\hline RTjadQ-F & CGACAAGCCGATGATCTACTACCC \\
\hline RTjadQ-R & GCGTGAGGTTCTTGGCGATGT \\
\hline RTjadS-F & GTCTTCCCGCCCAACCACG \\
\hline RTjadS-R & GCGAGGGAGCCAGCGTCAC \\
\hline RTjadT-F & CGACGAGGTGTACGGCACG \\
\hline RTjadT-R & CAGGATGCGTTCGGTCAGG \\
\hline RTjadU-F & CAGGTCAATCAGGTCAGCCACA \\
\hline RTjadU-R & CCGGTCGGACAGGATCAGC \\
\hline RTjadV-F & GACGAGCCGCAGGGCGAG \\
\hline RTjadV-R & CCGCTCCGCCACCATCCG \\
\hline RThrdB-SV-F & AGATTCCGCCAACCCAGTG \\
\hline RThrdB-SV-R & GAGCGTCGTCTCGTCTCGTC \\
\hline
\end{tabular}

Table 2 Primers used in this study (Continued)

\begin{tabular}{ll}
\hline other primers & \\
rrnFp-F & TGGAGGGAGATACGAGAACG \\
rrnFp-R & CCCAGAGTGAGGGCAGATT \\
MxylE-F & TGAACCGAAGTGGATAAGTT \\
MxylE-R & AGCCTTCAGATAGACACGGC \\
metK-F & CGGCGGCTGGAATGAATGACCC \\
metK-R & CAGGCCCGCGGCCTCGCGCA \\
sigR-F & GGGCGGAGATCAGCCAGGAAAG \\
sigR-R & TGACCCCGAGCCTTTCGCTTCGT \\
polB-F & GGTGAAGACGCCAACGAC \\
polB-R & GATCGGAGCGCGTACCAG \\
sanG-F & GGGGTACCGTGCGTCAACCTCATCCCG \\
sanG-R & GGAATTCGCTTGCCCGCTGGTCT \\
Kan-F & TCTAGAGATCCCCTGGATACCGCTCG \\
Kan-R & GGATCCGTACCCGAACCCCAGAGTC \\
\hline
\end{tabular}

amplified with primer $\mathrm{rrnFp}-\mathrm{F}$ and $\mathrm{rrnFp}-\mathrm{R}$ from $S$. coelicolor and ligated into pEASY-blunt to generate pEASY-blunt-rrnFp. The authenticity of PCR amplicon was verified by sequencing, and then it was ligated into the NotI-BamHI site of integrative vector pSET152 to give pSET152::rrnFp. Meanwhile, the DNA fragment containing the intact SCO5703 was amplified by PCR using primers PFrimP-F and PFrimP-R, then it was digested with


pSET152::rrnFp to generate pSET152::rrnFp::SCO5703. Finally, rimPDM was transformed with the plasmid pSET152::rrnFp::SCO5703 to generate the heterologous complemented strain of rimPDM (rimPDMC).

To construct the rimP-SC disruption mutant (rimPSCDM) of S. coelicolor M145, the DNA fragment corresponding to the upstream region of rimP-SC (extending from positions -1269 to +12 with respect to the rimP$S C$ translation start codon) was amplified by PCR using primers LrimP-SC-F and LrimP-SC-R and inserted into the HindIII-XbaI sites of pUC119::kan to generate pRIMPSC1. The DNA fragment corresponding to the downstream region of rimP-SC (extending from positions +403 to +1576 with respect to the rimP-SC translation start codon) was amplified by PCR using primers RrimP-SC-F and RrimP-SC-R and inserted into the $K p n I-E c o$ RI sites of pRIMPSC1. The resulting plasmid pRIMPSC2 was then digested with HindIII and EcoRI. A $3.3 \mathrm{~kb}$ DNA fragment was isolated and ligated into the corresponding sites of pKC1132 to give pRIMPSC3. The authenticity of all PCR amplicons was verified by sequencing. Subsequently, pRIMPSC3 was introduced into S. coelicolor M145 via ET12567/pUZ8002 by conjugal transfer and the transformants conferring kanamycin resistance $\left(\mathrm{Kan}^{\mathrm{r}}\right)$ and apramycin sensitivity $\left(\mathrm{Apr}^{\mathrm{S}}\right)$ were 
selected, and they were further confirmed by PCR using primers LrimP-SC-F and RrimP-SC-R. For complementation analysis, the fragment containing the intact rimP$S C$ with its putative promoter region was amplified with primers CrimP-SC-F and CrimP-SC-R and inserted into the EcoRV site of pSET152 to generate pRIMPSC4. Subsequently, pRIMPSC4 was introduced into rimP-SCDM by conjugal transfer and the complemented strain was confirmed by PCR.

To construct the rimP-SV disruption mutant (rimPSVDM) of S. venezuelae ATCC10712, the DNA fragment corresponding to the upstream region of $\operatorname{rimP}-S V$ was amplified by PCR using primers LrimP-SV-F and LrimPSV-R and inserted into the HindIII-XbaI sites of pKC1139 to generate pRIMPSV1. The DNA fragment corresponding to the downstream region of rimP-SV was amplified by PCR using primers RrimP-SV-F and RrimP-SV-R and inserted into the BamHI-EcoRV sites of pRIMPSV1 to generate pRIMPSV2. Kanamycin resistance gene was amplified by PCR using primers Kan-F and Kan-R and inserted into the BamHI-XbaI sites of pRIMPSV2 to generate pRIMPSV3. The authenticity of all PCR amplicons was verified by sequencing. Subsequently, pRIMPSV3 was introduced into S. venezuelae ATCC10712 via ET12567/pUZ8002 by conjugal transfer and transformants conferring kanamycin resistance $\left(\mathrm{Kan}^{\mathrm{r}}\right)$ and apramycin sensitivity $\left(\mathrm{Apr}^{\mathrm{s}}\right)$ were selected, and they were further confirmed by PCR using primers YZrimP-SV-F and YZrimP-SV-R. For complementation analysis, the fragment containing the intact rimP-SV with its putative promoter region was amplified using primers CrimP-SV-F and CrimP-SV-R and inserted into the EcoRV site of pSET152 to generate pRIMPSV4. Subsequently, pRIMPSV4 was introduced into rimPSV-DM by conjugal transfer and the complemented strain was confirmed by PCR.

For detection of MetK and SigR expression in $S$. coelicolor, the $3 \times$ FLAG-tagged system was applied and series of plasmids were constructed as follows: The DNA fragment containing the intact metK or sigR with its respective promoter was amplified by PCR with primers metK-F/metK-R or sigR-F/sigR-R and ligated into the StuI site of pIJ10500 to generate pIJ10500::metK or pIJ10500::sigR. The resulting plasmid pIJ10500::metK or pIJ10500::sigR was introduced into S. coelicolor M145 and rimP-SCDM by conjugal transfer, respectively. All the recombinant strains were subsequently confirmed by PCR amplification.

\section{RNA isolation, RT-PCR and real-time RT-PCR}

Total RNA were isolated from Streptomyces as described previously [36,37]. For reverse transcription PCR (RTPCR) and quantitative real-time reverse transcription PCR (real-time RT-PCR), the genomic DNA was removed from RNA samples with RQ1 RNase-free DNase (Promega), the synthesis of the first-strand cDNA was performed with Superscript III first-strand Synthesis System (Invitrogen) as described previously [38]. Reaction mixtures contained 6 pmol of random primers (Invitrogen) and $1 \mu \mathrm{g}$ of RNA in a total volume of $20 \mu \mathrm{l}$. The reverse transcription conditions were as follows: $65^{\circ} \mathrm{C}$ for $5 \mathrm{~min}, 25^{\circ} \mathrm{C}$ for $5 \mathrm{~min}, 50^{\circ} \mathrm{C}$ for $45 \mathrm{~min}, 55^{\circ} \mathrm{C}$ for $45 \mathrm{~min}$, and $72^{\circ} \mathrm{C}$ for $10 \mathrm{~min}$. RT-PCR reaction parameters were as follows: $95^{\circ} \mathrm{C}$ for $5 \mathrm{~min}$, followed by 30 amplification cycles consisting of $95^{\circ} \mathrm{C}$ for 30 seconds denaturation, $55^{\circ} \mathrm{C}$ for 30 seconds annealing, $72^{\circ} \mathrm{C}$ for 45 seconds extension and a final extension of $72^{\circ} \mathrm{C}$ for $10 \mathrm{~min}$. RT-PCR was performed without reverse transcriptase to test for DNA contamination in the RNA samples. After 30 cycles of amplification, the products were displayed on a $2 \%$ agarose gel and visualized by staining with ethidium bromide. Real-time RT-PCR was performed in 96-well rotor using the Eppendorf Realplex system, and the reaction mixtures were prepared as follows: Each reaction $(50 \mu \mathrm{l})$ contained $0.1-10 \mathrm{ng}$ of cDNA, $25 \mu \mathrm{l}$ Power SYBR Green PCR master mix (Toyobo, QPS-201), and 0.4 $\mu \mathrm{M}$ of forward and reverse primers respectively. The reaction conditions were maintained at $95^{\circ} \mathrm{C}$ for 30 seconds, followed by 40 amplification cycles consisting of 15 seconds denaturation at $95^{\circ} \mathrm{C}, 20$ seconds annealing at $60^{\circ} \mathrm{C}$ and 30 seconds extension at $72^{\circ} \mathrm{C}$. Fluorescence was measured at the end of each cycle. The final dissociation stage was run to generate a melting curve and consequently verify the specificity of the amplification products. Changes in levels of gene expression were calculated automatically with the Detection Software using the $\Delta \Delta C T$ method. The $h r d B$ was used as the housekeeping gene reference for RT-PCR and real-time RT-PCR.

\section{Construction of the xylE reporter system and Detection of translational fidelity}

The $x y l E$ was isolated from pIJ4083 by BglII and BamHI digestions, and then it was inserted into the BamHI site of pSET152 to generate pSET152::xylE. The DNA fragment containing the $r r n F$ promoter from pEASY-blunt-rrnFp was isolated and inserted in the upstream of $x y l E$ in pSET152 to generate pSET152::rrnFp::xylE. For the construction of mutated $x y l E$ reporter plasmid, pSET152:: rrnFp::xylE was used as the template for PCR amplification with primers MxylE-F and MxylE-R. The authenticity of PCR amplicon was verified by sequencing. The mutated plasmid pSET152::rrnFp::xylE", which contained alterations in the $5^{\prime}$ region of the $x y l E$ gene, was introduced a premature stop codon that abolished catechol dioxygenase activity. The reporter plasmids pSET152::rrnFp::xylE and pSET152::rrnFp::xylE" had the correct orientation of promoter in favor of transcriptional detection of $x y l E$, and 
then both of them were introduced into BW25113 and rimPDM to estimate translational fidelity. The translational error rate was calculated as activity of the wild-type catechol dioxygenase divided by that of mutated catechol dioxygenase in the same strain.

\section{Activity assays of XylE}

The detailed steps for activity detection of catechol dioxygenase were performed as described previously with minor revised [6]. For the recovery of recombinant strains, they were inoculated in $3 \mathrm{ml}$ of LB and incubated for $8-10 \mathrm{~h}$ at $37^{\circ} \mathrm{C}$ with shaking at $220 \mathrm{rpm}$. Then, the same amount of cells of each strain was transferred to $50 \mathrm{ml}$ of LB medium and incubated for $3.5,5.5,7,9$, 12 or $23 \mathrm{~h}$, respectively. Cultures of $1 \mathrm{ml}$ were harvested. After washing with $1 \mathrm{ml}$ sample buffer $(100 \mathrm{mM}$ phosphate buffer $\mathrm{pH}$ 7.5, $20 \mathrm{mM}$ EDTA pH 8.0, 10\% acetone), they were re-suspended in $0.5 \mathrm{ml}$ of sample buffer. The $0.5 \mathrm{ml}$ of cell suspension was sonicated on ice and $5 \mu \mathrm{l}$ of $10 \%$ Triton X-100 was added. It was placed on ice for $15 \mathrm{~min}$ and centrifuged for $10 \mathrm{~min}$ at 12,000 rpm, the supernatants were used for activity assays of XylE. The reaction mixture for measurement of catechol dioxygenase activity consisted of $0.5 \mathrm{ml}$ of assay buffer (10 mM phosphate buffer, $\mathrm{pH} 7.5,0.2 \mathrm{mM}$ catechol) and 5-50 $\mu \mathrm{l}$ of cell extract. Protein concentrations of cell extracts were measured according to the $\mathrm{BCA}$ protein assay method by using BSA as the standard. The catechol dioxygenase activity was calculated as the rate of change in optical density at $375 \mathrm{~nm}$ per minute per milligram of protein. The formula is as follows: catechol dioxygenase $(\mathrm{mU})=30.03 \times \Delta \mathrm{A}_{375} /$ time $(\mathrm{min})$.

\section{Western blotting of MetK and SigR in S. coelicolor}

For western blotting analysis, cell extracts from M145/pIJ10500::metK, M145/pIJ10500::sigR, rimP-SCDM /pIJ10500::metK and rimP-SCDM/pIJ10500::sigR, grown in the GYM medium at different time points, were sonicated on ice. The concentration of total protein was determined by BCA protein assay using BSA as the standard sample. Equal concentrations of proteins $(50 \mu \mathrm{g})$ from different time-point samples were loaded onto $12 \%$ polyacrylamide/SDS gel electrophoresis. Proteins in the gels were transferred to PVDF western blotting membranes (Roche, Germany) and probed with monoclonal ANTI-FLAG M2 antibody (Sigma-aldrich, USA) as recommended by the manufacturer. The antibodies on the membranes were hybridized with the goat Anti-Mouse IgG-HRP as secondary antibody (Jackson, USA) and the position of tagged-FLAG was visualized through cECL western blot kit (CWBIO Corporation, China).

\section{Heterologous expression and bioassays of polyoxin and nikkomycin}

The entire polyoxin and nikkomycin biosynthetic gene clusters were ligated with integrated vector pSET152 to generate $\mathrm{pPOL}$ and $\mathrm{pNIK}$, respectively $[34,35]$. Then they were introduced into M145 and rimP-SCDM to generate recombinant strains $\mathrm{M} 145 / \mathrm{pPOL}$, rimP-SCDM/pPOL, M145/pNIK and rimP-SCDM/pNIK. Recombinant strains containing the entire polyoxin or nikkomycin biosynthetic gene cluster were confirmed by PCR amplification using primers polB-F/polB-R or sanG-F/sanG-R respectively. Then 5 days' fermentation broths of all the recombinant strains were measured by a disk agar diffusion method using $A$. longipes as indicator strain.

\section{Competing interests}

The authors declare that they have no competing interests.

\section{Authors' contributions}

YP and CL performed the experiments of S. coelicolor and S. venezuelae respectively. HD carried out the HPLC analysis of ppGpp. LY assisted with experiments. YP wrote the draft manuscript. GL and HT supervised the whole work and revised the manuscript. All authors read and approved the final manuscript.

\section{Acknowledgements}

We thank Professor Mervyn Bibb (John Innes Centre, Norwich, UK) for critical reading in preparation of this manuscript and Chris D. Den Hengst for providing plJ10500 (John Innes Centre, Norwich, UK). This work was supported by grants from the National Natural Science Foundation of China (Grant Nos. 31030003, 31200929 and 31270110) and Ministry of Science and Technology of China (Grant No. 2009CB118905).

Received: 28 March 2013 Accepted: 26 June 2013

Published: 2 July 2013

\section{References}

1. Neidhardt F, Ingraham J, Schaechter M: Physiology of the Bacterial Cell. A Molecular Approach. Sunderland, MA: Sinauer Associates, Inc, Publishers; 1990.

2. Nord S, Bylund GO, Lovgren JM, Wikstrom PM: The RimP protein is important for maturation of the 30 S ribosomal subunit. J Mol Biol 2009, 386:742-753.

3. Bunner AE, Nord S, Wikstrom PM, Williamson JR: The effect of ribosome assembly cofactors on in vitro $30 \mathrm{~S}$ subunit reconstitution. J Mol Biol 2010, 398:1-7.

4. Shajani Z, Sykes MT, Williamson JR: Assembly of bacterial ribosomes. Annu Rev Biochem 2011, 80:501-526.

5. Hopwood DA: Forty years of genetics with Streptomyces: from in vivo through in vitro to in silico. Microbiology 1999, 145(Pt 9):2183-2202.

6. Kieser T, Bibb MJ, Buttner MJ, Chater KF, Hopwood DA: Practical Streptomyces Genetics. Norwich, England: John Innes Foundation; 2000.

7. Malpartida F, Hopwood DA: Molecular cloning of the whole biosynthetic pathway of a Streptomyces antibiotic and its expression in a heterologous host. Nature 1984, 309:462-464.

8. Cerdeno AM, Bibb MJ, Challis GL: Analysis of the prodiginine biosynthesis gene cluster of Streptomyces coelicolor A3(2): new mechanisms for chain initiation and termination in modular multienzymes. Chem Biol 2001, 8:817-829.

9. Hojati Z, Milne C, Harvey B, Gordon L, Borg M, Flett F, Wilkinson B, Sidebottom PJ, Rudd BA, Hayes MA, et al: Structure, biosynthetic origin, and engineered biosynthesis of calcium-dependent antibiotics from Streptomyces coelicolor. Chem Biol 2002, 9:1175-1187.

10. Corre C, Challis GL: Evidence for the unusual condensation of a diketide with a pentulose in the methylenomycin biosynthetic pathway of Streptomyces coelicolor A3(2). ChemBioChem 2005, 6:2166-2170. 
11. Challis GL: Mining microbial genomes for new natural products and biosynthetic pathways. Microbiology 2008, 154:1555-1569.

12. Nett M, Ikeda H, Moore BS: Genomic basis for natural product biosynthetic diversity in the actinomycetes. Nat Prod Rep 2009, 26:1362-1384

13. Okamoto-Hosoya Y, Sato TA, Ochi K: Resistance to paromomycin is conferred by rpsL mutations, accompanied by an enhanced antibiotic production in Streptomyces coelicolor A3(2). J Antibiot 2000, 53:1424-1427.

14. Ochi K, Okamoto S, Tozawa Y, Inaoka T, Hosaka T, Xu J, Kurosawa K: Ribosome engineering and secondary metabolite production. Adv Appl Microbiol 2004, 56:155-184.

15. Okamoto S, Lezhava A, Hosaka T, Okamoto-Hosoya Y, Ochi K: Enhanced expression of S-adenosylmethionine synthetase causes overproduction of actinorhodin in Streptomyces coelicolor A3(2). J Bacteriol 2003, 185:601-609.

16. Sharma D, Cukras AR, Rogers EJ, Southworth DR, Green R: Mutational analysis of $\mathrm{S} 12$ protein and implications for the accuracy of decoding by the ribosome. J Mol Biol 2007, 374:1065-1076.

17. Ogle JM, Murphy FV, Tarry MJ, Ramakrishnan V: Selection of tRNA by the ribosome requires a transition from an open to a closed form. Cell 2002, 111:721-732.

18. Ogle JM, Brodersen DE, Clemons WM Jr, Tarry MJ, Carter AP, Ramakrishnan $\mathrm{V}$ : Recognition of cognate transfer RNA by the $30 \mathrm{~S}$ ribosomal subunit. Science 2001, 292:897-902.

19. Wang $G$, Inaoka T, Okamoto S, Ochi K: A novel insertion mutation in Streptomyces coelicolor ribosomal S12 protein results in paromomycin resistance and antibiotic overproduction. Antimicrob Agents Chemother 2009, 53:1019-1026.

20. Hesketh A, Ochi K: A novel method for improving Streptomyces coelicolor $\mathrm{A} 3(2)$ for production of actinorhodin by introduction of $r p s L$ (encoding ribosomal protein $\mathrm{S12}$ ) mutations conferring resistance to streptomycin. J Antibiot 1997, 50:532-535

21. Hosaka T, Xu J, Ochi K: Increased expression of ribosome recycling factor is responsible for the enhanced protein synthesis during the late growth phase in an antibiotic-overproducing Streptomyces coelicolor ribosomal rpsL mutant. Mol Microbiol 2006, 61:883-897.

22. Okamoto-Hosoya Y, Hosaka T, Ochi K: An aberrant protein synthesis activity is linked with antibiotic overproduction in rpsL mutants of Streptomyces coelicolor A3(2). Microbiology 2003, 149:3299-3309.

23. Tamehiro N, Hosaka T, Xu J, Hu H, Otake N, Ochi K: Innovative approach for improvement of an antibiotic-overproducing industrial strain of Streptomyces albus. Appl Environ Microbiol 2003, 69:6412-6417.

24. Wang G, Tanaka Y, Ochi K: The G243D mutation (afsB mutation) in the principal sigma factor sigmaHrdB alters intracellular ppGpp level and antibiotic production in Streptomyces coelicolor A3(2). Microbiology 2010, 156:2384-2392.

25. Wang G, Hosaka T, Ochi K: Dramatic activation of antibiotic production in Streptomyces coelicolor by cumulative drug resistance mutations. Appl Environ Microbiol 2008, 74:2834-2840.

26. Wohlgemuth I, Pohl C, Rodnina MV: Optimization of speed and accuracy of decoding in translation. EMBO J 2010, 29:3701-3709.

27. Zeng $\mathrm{H}$, Tan $\mathrm{H}$, Li J: Cloning and function of sanQ: a gene involved in nikkomycin biosynthesis of Streptomyces ansochromogenes. Curr Microbiol 2002, 45:175-179.

28. Yang K, Han L, He J, Wang L, Vining LC: A repressor-response regulator gene pair controlling jadomycin B production in Streptomyces venezuelae ISP5230. Gene 2001, 279:165-173.

29. Anderson TB, Brian P, Champness WC: Genetic and transcriptional analysis of $a b s A$, an antibiotic gene cluster-linked two-component system that regulates multiple antibiotics in Streptomyces coelicolor. Mol Microbiol 2001, 39:553-566.

30. Wang L, Tian $X$, Wang J, Yang $H$, Fan $K, X u$ G, Yang $K$, Tan $H$ : Autoregulation of antibiotic biosynthesis by binding of the end product to an atypical response regulator. Proc Natl Acad Sci U S A 2009, 106:8617-8622.

31. Doull JL, Singh AK, Hoare M, Ayer SW: Conditions for the production of jadomycin B by Streptomyces venezuelae ISP5230: effects of heat shock, ethanol treatment and phage infection. J Ind Microbiol 1994, 13:120-125.

32. Datsenko KA, Wanner BL: One-step inactivation of chromosomal genes in Escherichia coli K-12 using PCR products. Proc Natl Acad Sci U S A 2000, 97:6640-6645.
33. Paget MS, Chamberlin L, Atrih A, Foster SJ, Buttner MJ: Evidence that the extracytoplasmic function sigma factor sigmaE is required for normal cell wall structure in Streptomyces coelicolor A3(2). J Bacteriol 1999, 181:204-211.

34. Liao G, Li J, Li L, Yang H, Tian Y, Tan H: Cloning, reassembling and integration of the entire nikkomycin biosynthetic gene cluster into Streptomyces ansochromogenes lead to an improved nikkomycin production. Microb Cell Fact 2010, 9:6.

35. Li J, Li L, Feng C, Chen Y, Tan H: Novel polyoxins generated by heterologously expressing polyoxin biosynthetic gene cluster in the sanN inactivated mutant of Streptomyces ansochromogenes. Microb Cell Fact 2012, 11:135.

36. Liu G, Tian Y, Yang H, Tan H: A pathway-specific transcriptional regulatory gene for nikkomycin biosynthesis in Streptomyces ansochromogenes that also influences colony development. Mol Microbiol 2005, 55:1855-1866.

37. Pan Y, Liu G, Yang H, Tian Y, Tan H: The pleiotropic regulator AdpA-L directly controls the pathway-specific activator of nikkomycin biosynthesis in Streptomyces ansochromogenes. Mol Microbiol 2009, 72:710-723.

38. Pan $Y$, Wang $L$, He $X$, Tian $Y$, Liu G, Tan H: SabR enhances nikkomycin production via regulating the transcriptional level of sanG, a pathwayspecific regulatory gene in Streptomyces ansochromogenes. BMC Microbiol 2011, 11:164.

\section{doi:10.1186/1475-2859-12-65}

Cite this article as: Pan et al:: Disruption of rimP-SC, encoding a ribosome assembly cofactor, markedly enhances the production of several antibiotics in Streptomyces coelicolor. Microbial Cell Factories $201312: 65$.

\section{Submit your next manuscript to BioMed Central and take full advantage of:}

- Convenient online submission

- Thorough peer review

- No space constraints or color figure charges

- Immediate publication on acceptance

- Inclusion in PubMed, CAS, Scopus and Google Scholar

- Research which is freely available for redistribution 